\title{
Knowledge, attitude and techniques of breastfeeding among Nigerian mothers from a semi-urban community
}

\author{
Chidozie E Mbada ${ }^{1 *}$, Adekemi E Olowookere ${ }^{2}$, Joel O Faronbi², Folasade C Oyinlola-Aromolaran', \\ Funmilola A Faremi ${ }^{2}$, Abiola O Ogundele ${ }^{1}$, Taofeek O Awotidebe ${ }^{1}$, Adepeju A Ojo ${ }^{1}$ and Oluwakemi A Augustine ${ }^{2}$
}

\begin{abstract}
Background: Mothers' poor knowledge and negative attitude towards breastfeeding may influence practices and constitute barriers to optimizing the benefits of the baby-friendly initiative. This study assessed breastfeeding knowledge, attitude and techniques of postures, positioning, hold practice and latch-on among Nigerian mothers from a Semi-Urban community.

Methods: Three hundred and eighty three consenting lactating mothers who have breastfed for 6 months and up to two years volunteered for this cross-sectional survey, yielding a response rate of $95.7 \%$. A self-administered questionnaire that sought information on maternal socio-demographic variables, knowledge, attitudes and breastfeeding techniques of mothers was employed.

Results: Based on cumulative breastfeeding knowledge and attitude scores, $71.3 \%$ of the respondents had good knowledge while $54.0 \%$ had positive attitude. Seventy one point three percent practiced advisable breastfeeding posture. Sitting on a chair to breastfeed was common (62.4\%); and comfort of mother/baby (60.8\%) and convenience (29.5\%) were the main reasons for adopting breastfeeding positions. Cross-cradle hold (80.4\%), football hold technique (13.3\%), breast-to-baby (18.0\%) and baby-to-breast latch-on (41.3\%) were the common breastfeeding techniques. A majority of the respondents (75.7\%) agreed that neck flexion, slight back flexion, arm support with pillow and foot rest was essential during breastfeeding. There was no significant association between breastfeeding posture practice and each of cumulative breastfeeding knowledge score levels $\left(X^{2}=0.044 ; p=0.834\right)$ and attitude score levels $\left(X^{2}=0.700\right.$; $p=0.403)$.

Conclusion: Nigerian mothers demonstrated good knowledge and positive attitude towards breastfeeding. Most of the mothers practiced advisable breastfeeding postures, preferred sitting on a chair to breastfeed and utilized cross-cradle hold and baby-to-breast latch-on.
\end{abstract}

\section{Background}

Breastfeeding is the act of milk transference from mother to baby [1] that is needed for the survival and healthy growth of the baby into an adult [2,3]. Breastfeeding creates an inimitable psychosocial bond between the mother and baby $[4,5]$, enhances modest cognitive development [6] and it is the underpinning of the infant's wellbeing in the first year of life [5,7] even into the second year of life with appropriate complementary foods from 6

\footnotetext{
* Correspondence: doziembada@yahoo.com

'Department of Medical Rehabilitation, College of Health Sciences, Obafemi Awolowo University, lle - Ife, Nigeria

Full list of author information is available at the end of the article
}

months [8]. Furthermore, breastfeeding reduces the risk of neonatal complications [9], respiratory and other varieties of illnesses [10-13].

Based on anecdotal and empirical evidence on the benefits of breastfeeding to the mother and baby, the World Health Organization (WHO) [8] has recommended 2 year breastfeeding; first 6 months exclusive breastfeeding; more than 8 times breastfeeding of the baby per day in the first 3 months of an infant's life. The WHO and the United Nations Children's Fund (UNICEF) global effort to implement practices that protect, promote and support breastfeeding through the Baby-Friendly Hospital Initiative has recorded attendant successes [14]. However, a gamut of 
factors not limited to race and cultural beliefs [15,16], maternal characteristics $[17,18]$, infant health problems [17], socio-economic status $[19,20]$ and some psychosocial factors [21,22] may hamper the full realization of the baby-friendly initiative. Information about the beliefs and knowledge that may constitute barriers and in turn influence practices are needed in order to optimally utilize the benefits of the baby-friendly initiative. Consequently, a number of studies have assessed knowledge, attitude and practice of breastfeeding in different parts of the world; however, such studies are limited among Nigerian mothers [23-26]. Furthermore, there is an apparent dearth of empirical data on breastfeeding techniques among nursing mothers in sub-Sahara Africa (SSA). This study assessed breastfeeding knowledge, attitude and techniques of postures, positioning, hold practice and latch-on among Nigerian mothers.

\section{Methods}

A cross-sectional survey of lactating mothers who had breastfed for not less than six months and up to two years was carried out. These mothers who were attending post-natal clinics for immunization were recruited using consecutive sampling technique. Five governmentowned post-natal clinics namely Ife Hospital Unit of the Obafemi Awolowo University Teaching Hospital Complex (OAUTHC), Urban Comprehensive Health Centre (UCHC) of the OAUTHC, Eleyele, Enuwa Primary Health Center, Comprehensive Health Center Aderemi and Okeitubu Comprehensive Health Center Modakeke in Ile-Ife, were purposively selected based on the availability and practice of the baby-friendly programmes in the facilities. Ile - Ife is ancient semi-urban settlement and the traditional home of the Yoruba civilization. Ile-Ife is located in the south-western part of Nigeria bordered by Ibadan (the largest city in SSA) on the West and by Ondo town on the east.

Ethical approval for the study was sought from the Ethics and Research Committee of the OAUTHC. All the respondents gave signed informed consent prior to participation. The questionnaire for the study was adapted from previous studies on knowledge, attitude and practice of breastfeeding [27-29]. The face validity of the questionnaire was determined by expert review in a pilot study. The reliability of the questionnaire was tested by a testretest method. The copies of the questionnaire were first administered to 20 breastfeeding mothers attending the $\mathrm{UCHC}$ and were re-administered 7 days after. The questionnaire was translated into Yoruba language and backtranslated into the original language (English). The reliability of the Yoruba version was assessed in a pilot study by a test-retest method among 20 mothers attending the UCHC, observing 7 days between test and re-test. Testretest reliability of the English version of the questionnaire yielded a correlation coefficient of $\mathrm{r}=0.967$ at $\mathrm{p}=0.001$. The items of the Yoruba language (the local language among the respondents) version of the questionnaire yielded agreements percentage that ranged from 94 to $100 \%$, and the corresponding kappas ranged from 0.76 to 1.00 .

The self-administered questionnaire sought information on socio-demographic and maternal characteristics, knowledge and attitude towards breastfeeding, and the most usual breastfeeding techniques of postures, positioning, hold practice and latch-on. Knowledge and attitude regarding breastfeeding were rated on a likert scale of 1 to 5 and was transformed to a 100 point scale by multiplying by 20 . A pictorial assessment of breastfeeding postures was also included in the questionnaire.

\section{Data analyses}

Data on maternal socio-demographic characteristics, breastfeeding awareness, postures, positioning, hold practice and latching techniques were summarized using descriptive statistics of frequency and percentages. The respondents rating of questionnaire items regarding knowledge and attitude about breastfeeding were summarized using mean and standard deviation. Chi-square test was used to compare each of breastfeeding knowledge, attitude and position practices based on parity and history of previous training on breastfeeding. Also chi-square was used to test association between breastfeeding position practice and each of cumulative breastfeeding knowledge score levels and attitude score levels. The level of significance was set at $\mathrm{p}<0.05$. Data were analyzed with Statistical Package for Social Sciences (SPSS) software (version 16).

\section{Results}

A total of 400 questionnaires were distributed to breastfeeding women. However, 383 were returned and found valid for analysis yielding a responsive rate of $95.7 \%$. The maternal socio-demographic characteristics are presented in Table 1. The mean age of the respondent was $29.0 \pm$ 4.96 years. Information on breastfeeding awareness among the respondents is presented in Table 2. A majority (88.0\%) of the respondents reported to have heard about Exclusive Breastfeeding (EBF) and hospital was the source of information respectively. More than half (69.5\%) of the respondents had previous EBF training. Table 3 shows knowledge and attitude of the respondents about breastfeeding. On a scale of 100, knowledge item 'breastfeeding promote mother-baby bonding' was scored 76, indicating a high agreement, while item 'three month of breastfeeding is long enough' had the lowest score of 36. Regarding attitude to breastfeeding, on a scale of 100 , items 'breastfeeding is easier than feeding infant on formula' 'community encourages breastfeeding over feeding infant formula' and 'doctors and nurses encourage breastfeeding' were 
Table 1 Maternal socio-demographic characteristics ( $N=383)$

\begin{tabular}{lcc}
\hline Variable & $\mathbf{n}$ & \% \\
\hline Religion & 275 & 71.8 \\
Christianity & 108 & 28.2 \\
Islam & & \\
Education & 33 & 8.6 \\
Pry & 157 & 41.0 \\
Secondary & 185 & 48.3 \\
Tertiary & 8 & 2.1 \\
MSC & & \\
Occupation & 62 & 16.2 \\
Unemployed & 157 & 41.0 \\
Private unskilled & 76 & 19.8 \\
Private skilled & 62 & 16.2 \\
Public junior & 26 & 6.8 \\
Public senior & & \\
Age (in years) & 224 & 41.5 \\
$\leq 30$ & 159 & \\
$>30$ & &
\end{tabular}

scored 76 respectively. On the other hand, 'breastfeeding has effect on care of other family members and on marital relationship' was the least rated with a score of 42 .

Table 4 show results on the breastfeeding postures, positioning, hold and latching practices. $71.3 \%$ of the respondents practiced advisable breastfeeding positioning. More than half $(62.4 \%)$ of the respondents preferred sitting on a chair to breastfeed. The main reasons for positions

Table 2 Information on breastfeeding awareness among the respondents

\begin{tabular}{lcc}
\hline Variable & $\mathbf{n}$ & $\%$ \\
\hline Heard about EBF? & 378 & 88.0 \\
Yes & 5 & 1.3 \\
No & & \\
EBF information source & 337 & 88.0 \\
Hospital & 46 & 12.0 \\
Others & 266 & 69.5 \\
Have you received any training on EBF? & 117 & 30.5 \\
Yes & 3 & \\
No & 86 & 22.5 \\
How many years should a baby breastfeed? & 43.9 \\
6 months & 168 & 32.9 \\
Within one year & 126 & \\
Within 18 months & 3 & \\
Up to 2 years & & \\
\hline
\end{tabular}

adopted during breastfeeding were for comfort of mother/ baby (60.8\%) and convenience (29.5\%). A majority $(80.4 \%)$ of the respondents mostly practiced crosscradle breastfeeding position while $13.3 \%$ practiced football hold. The rates of breast-to-baby and baby-tobreast latch-on practices were $18.0 \%$ and $41.3 \%$ respectively. A majority (75.7\%) of the respondents reported that neck flexion, slight back flexion, arm support with pillow and foot rest is essential ergonomic posture while sitting to breastfeeding. Chi-square analyses of differences in breastfeeding knowledge, attitude and position practices are presented in Table 5 . There was no significant association between breastfeeding posture practice and each of cumulative breastfeeding knowledge score levels $\left(\mathrm{X}^{2}=0.044 ; \mathrm{p}=0.834\right)$ and attitude scores $\left(\mathrm{X}^{2}=\right.$ $0.700 ; p=0.403)$. However, there was a significant association between having previous training on breastfeeding and cumulative breastfeeding knowledge score level $\left(\mathrm{X}^{2}=6.104 ; \mathrm{p}=0.013\right)$ while parity was significantly associated with breastfeeding posture practice $\left(\mathrm{X}^{2}=\right.$ 10.022; $\mathrm{p}=0.002)$.

\section{Discussion}

This study assessed breastfeeding knowledge, attitude and practices of postures, positioning, hold techniques and latch-on among Nigerian mothers. From the result, there was a high awareness of EBF and full breastfeeding among the mothers. This finding is consistent with previous reports from Nigeria that showed high rates of awareness of EBF among working class mothers and women who have no paid occupation outside the home and instead focus their lives on motherhood [23,30,31]. The high level of awareness about EBF and full breastfeeding in this study may be attributed to the babyfriendly initiative programme being practiced at the centres where the study was conducted. From this study, information regarding breastfeeding was gotten mostly from hospitals. In line with this result, several studies have proved that baby-friendly hospitals are important channels for dissemination of knowledge about breastfeeding [27,32,33]. According to Bartington et al. [34] mothers who delivered in baby friendly maternity hospital units are more likely to initiate breastfeeding than those who did not deliver in baby friendly hospitals.

This study's findings on the knowledge of the mothers regarding breastfeeding revealed that majority of the women in this study had good knowledge about breastfeeding. This finding confirms previous results that Nigerian mothers have good knowledge of EBF [24-26,35]. In consonance with literature on knowledge about breastfeeding, most of the mothers in this study agrees that breastfeeding promotes mother-baby bonding [36,37], frequent breastfeeding in the early period can help reduce jaundice [38,39], and that growth pattern of breastfed infants differ from 
Table 3 Knowledge and attitude about breastfeeding

\begin{tabular}{|c|c|}
\hline Item & $\begin{array}{c}\text { Average score/ } \\
(100 \%)\end{array}$ \\
\hline \multicolumn{2}{|l|}{ KNOWLEDGE } \\
\hline $\begin{array}{l}\text { 1. Woman who is fully breastfeeding is less likely to become pregnant } 3 \text { months after delivery than a woman who is formula } \\
\text { feeding }\end{array}$ & 48 \\
\hline 2. Breastfeeding decreases diarrhea & 46 \\
\hline 3. Breastfeeding is a good contraceptive method & 48 \\
\hline 4. Breastfeeding promote mother-baby bonding & 76 \\
\hline 5. Feeding infant formula keeps the body well shaped and prevent over weight & 70 \\
\hline 6. Frequent breastfeeding in the early period can help reduce jaundice & 66 \\
\hline 7. Growth pattern of breastfed infants differ from those of formula fed & 66 \\
\hline $\begin{array}{l}\text { 8. If a breastfed infant has not regained his birth weight by two weeks of age the mother should be encouraged to begin } \\
\text { supplementing with formula. }\end{array}$ & 62 \\
\hline 9. Initial breast production of yellow water (colostrums) is nutritionally useless for the baby and should be discarded & 52 \\
\hline 10. Supplemental feeding is detrimental to the establishment of a good milk supply & 48 \\
\hline 11. Three month of breastfeeding is long enough & 36 \\
\hline 12. Work places provide designated areas for breastfeeding & 36 \\
\hline \multicolumn{2}{|l|}{ ATTITUDE } \\
\hline 1. Breastfeeding has effect on care of other family members and on marital relationship & 42 \\
\hline 2. Breastfeeding is a good way to decrease family expenses & 72 \\
\hline 3. Breastfeeding is easier than feeding infant on formula & 76 \\
\hline 4. Community encourages breastfeeding over feeding infant formula & 76 \\
\hline 5. Doctors and nurses encourage breastfeeding & 76 \\
\hline 6. Feeling shy of breastfeeding in public places & 74 \\
\hline 7. I'm not comfortable with breastfeeding & 54 \\
\hline 8. It is not difficult for breastfeeding mother to care for family & 62 \\
\hline 9. It is usually advisable for babies to receive a formula feed before the first breastfeed & 50 \\
\hline 10. Maternity leave of 3 months is enough to successful breastfeeding & 48 \\
\hline 11. Medical practitioners have no role in breastfeeding & 48 \\
\hline 12. Mother of an infant who feels that she has insufficient milk should top up with, a bottle after each feed. & 56 \\
\hline
\end{tabular}

those of formula fed [40-42]. The mothers in this study consider three month maternity leave duration as insufficient to encourage EBF and advocated for policies on longer leave for new mothers and availability of designated child care centers at workplaces to facilitate successful breastfeeding. A previous study reported dissatisfaction of mothers with the length of maternity leave and lack of right environment for breastfeeding at workplaces among Jordanian women [27]. Ong et al. [43] reported that inadequate facility for breastfeeding at workplace significantly reduces the duration of breastfeeding among working mothers. Similarly, extensions of maternity leave up to the first six month of child's age to achieve optimal level of EBF practices was advocated in another study among Ethiopian women [44]. In order to promote optimal duration for EBF, the WHO advocated for minimum enabling conditions such as paid maternity leave, part-time work arrangements, facilities for expressing and storing breast milk and breastfeeding breaks for women in paid employment [45].

From this study, more than fifty percent of the women had positive attitude towards breastfeeding. Studies have found a direct correlation between positive attitude to breastfeeding and optimal EBF practice [46-48]. Positive parental attitudes towards infant feeding are reported to be an important component in child nutritional health [49]. In evaluating attitudes towards breastfeeding, perception of breastfeeding as easier than feeding infant formula and the roles of community and health workers in encouraging breastfeeding over feeding infant formula were the most rated influencing factors in this study. Other studies have implicated several factors for the different attitudes put forward by mothers towards breastfeeding. These include partner or friend/family support 
Table 4 Breastfeeding postures, positioning, hold practice and latching techniques

\begin{tabular}{|c|c|c|}
\hline Variable & n & $\%$ \\
\hline \multicolumn{3}{|l|}{ Breastfeeding posture practice } \\
\hline Advisable & 273 & 71.3 \\
\hline Not advisable & 110 & 28.7 \\
\hline \multicolumn{3}{|l|}{ Breastfeeding position practice } \\
\hline Side-lying & 47 & 12.3 \\
\hline Sitting on a mat & 35 & 9.1 \\
\hline Sitting on the side of bed & 62 & 16.2 \\
\hline Sitting on a chair & 239 & 62.4 \\
\hline \multicolumn{3}{|l|}{ Reason for Breastfeeding position practice } \\
\hline Comfort of the mother/baby & 233 & 60.8 \\
\hline Convenience & 113 & 29.5 \\
\hline Religion & 8 & 2.1 \\
\hline No obvious reason & 29 & 7.6 \\
\hline \multicolumn{3}{|l|}{ Breastfeeding hold practice } \\
\hline Cradle hold & 7 & 1.8 \\
\hline Football hold & 51 & 13.3 \\
\hline Side-lying & 17 & 4.5 \\
\hline Cross-cradle hold & 308 & 80.4 \\
\hline \multicolumn{3}{|l|}{ Latch-on to breast practice } \\
\hline Mothers who specified breast-to-baby & 69 & 18.0 \\
\hline Mothers who specified baby-to- breast & 158 & 41.3 \\
\hline Mothers who specified breast-to-baby and baby-to- breast & 113 & 29.5 \\
\hline Mothers who gave no specific answer & 43 & 11.2 \\
\hline \multicolumn{3}{|l|}{ Essential ergonomic posture while sitting to breastfeeding } \\
\hline Slight neck flexion & 33 & 8.6 \\
\hline Slight back upper back flexion & 11 & 2.9 \\
\hline Foot rest & 26 & 6.8 \\
\hline Arm support (pillow) & 23 & 6.0 \\
\hline All of the above & 290 & 75.7 \\
\hline
\end{tabular}

[48], fear of inadequate milk supply [25], ambivalent link of breastfeeding with sagging breast $[50,51]$ and sociocultural and psychological factors [52].

Compared with empirical findings, there are several anecdotal submissions and expert opinions on breastfeeding techniques which are often unreferenced or published as non-refereed materials. However, some previous studies have described breastfeeding techniques and habits; and optimal positions to stimulate breastfeeding and minimize fatigue [53-56]. To our knowledge, this study provided the first empirical analysis of techniques of breastfeeding posture, positioning of mother and baby, hold techniques and latch-on to breast or attachment practices among nursing mothers in SSA. From this study, most of the mothers were adjudged to be practicing advisable breastfeeding postures based on the pictorial self-
Table 5 Chi-square analyses of differences in breastfeeding knowledge, attitude and position practices $(\mathbf{N}=\mathbf{3 8 3})$

\begin{tabular}{|c|c|c|c|c|}
\hline & \multicolumn{2}{|c|}{ Knowledge of breastfeeding } & \multirow[b]{2}{*}{$x^{2}$} & \multirow[b]{2}{*}{ p-value } \\
\hline & Good n (\%) & Poor n (\%) & & \\
\hline \multicolumn{5}{|l|}{ Parity } \\
\hline Primiparous & $98(74.2)$ & $34(25.8)$ & 0.864 & 0.353 \\
\hline Multiparous & 175(69.7) & $76(30.3)$ & & \\
\hline \multicolumn{5}{|c|}{ Previous training on breastfeeding } \\
\hline Yes & 195(71.4) & $71(28.6)$ & 6.104 & 0.013 \\
\hline \multirow[t]{3}{*}{ No } & $71(64.5)$ & $46(35.5)$ & & \\
\hline & \multicolumn{2}{|c|}{ Attitude towards breastfeeding } & & \\
\hline & Good & Poor & $x^{2}$ & p-value \\
\hline \multicolumn{5}{|l|}{ Parity } \\
\hline Primiparous & $71(53.8)$ & $61(46.2)$ & 0.088 & 0.766 \\
\hline Multiparous & $139(55.4)$ & $112(44.6)$ & & \\
\hline \multicolumn{5}{|c|}{ Previous training on breastfeeding } \\
\hline Yes & $144(54.1)$ & $122(45.9)$ & 0.003 & 0.958 \\
\hline \multirow[t]{3}{*}{ No } & $63(53.8)$ & $54(46.2)$ & & \\
\hline & \multicolumn{2}{|c|}{ Breastfeeding posture practice } & & \\
\hline & Advisable & Not advisable & $x^{2}$ & p-value \\
\hline \multicolumn{5}{|l|}{ Parity } \\
\hline Primiparous & $111(84.1)$ & $21(15.9)$ & 10.022 & 0.002 \\
\hline Multiparous & $236(94.0)$ & $15(6.0)$ & & \\
\hline \multicolumn{5}{|c|}{ Previous training on breastfeeding } \\
\hline Yes & $251(94.4)$ & 15(5.6) & 1.818 & 0.178 \\
\hline No & 106(90.6) & $11(9.4)$ & & \\
\hline \multicolumn{5}{|c|}{ Knowledge of breastfeeding } \\
\hline Good & $254(71.2)$ & 103(28.8) & 0.044 & 0.834 \\
\hline Poor & 19(73.1) & $7(26.9)$ & & \\
\hline \multicolumn{5}{|c|}{ Attitude towards breastfeeding } \\
\hline Positive & 195(94.2) & $12(5.8)$ & 0.700 & 0.403 \\
\hline Negative & $162(92.1)$ & $14(7.9)$ & & \\
\hline
\end{tabular}

report assessment of breastfeeding practice. However, controversies exist about the ideal sitting position, as there have been different recommendations over the years as regards the best sitting posture. More so, there is lack of consensus on the best breastfeeding postures. This present study chooses to designate conformity with recommendations on good sitting in literature as "advisable breastfeeding posture". Considering there is no empirical evidence on the correct or standard breastfeeding posture in literature. However, Claus et al. [57] submitted that the best sitting posture should involve a minimal amount of stress and strain and should be conducive to maximize efficiency in the use of the body part. Therefore, this study conceived breastfeeding posture as the position assumed by the mothers for the purpose of breastfeeding. Nonetheless, 
sitting postures that deviate from standard recommendations for the workplace was deemed inappropriate for breastfeeding. Mbada et al. [58] submitted that inappropriate postures for prolonged time, as it is the case in breastfeeding, could lead to end range loading of periarticular structures and result in mechanical deformation of normal soft tissues. However, breastfeeding posture practice was not influenced by mothers' knowledge and attitude regarding breastfeeding.

Unfortunately, there is an apparent dearth of empirical studies to compare this finding on posture practice in breastfeeding. A significant limitation of this study's finding on posture practice in breastfeeding is the heterogeneity of the sample. Expected postures would be quite different if babies were currently 6 months old or currently 18 months old, as a result, the age of the child and the experience of the mother become important determinants.

Sitting on a chair to breastfeed was the most preferred breastfeeding position by mothers in this study and it was reportedly due to comfort of mother/baby and convenience. Sitting on the bedside to breastfeed was the second most utilized breastfeeding position while breastfeeding in side-lying was the least utilized position. Sitting upright in a breast-to-baby latch-on and holding baby in a cradle, cross-cradle or football position is considered as the mainstream and traditional approach in breastfeeding [59,60]. Some breastfeeding experts may traditionally have insisted on upright sitting postures because of etiquette, leaning back perhaps being associated with slouching or an unkempt appearance [59] and also that sitting upright for breastfeeding allows the women's breasts to 'point downwards and outwards' allowing for attachment of baby to the breast [61]. However, sitting upright is believed to be fraught with potential for muscular fatigue and the most difficult body posture to sustain [62]. Furthermore, upright sitting breastfeeding position with no support for the back and may overstress the musculature of the trunk muscles [58]. Inadvertently, mothers are often advised to initiate breastfeeding in side-lying especially after caesarean section [59]. Additionally, breastfeeding in side-lying is thought to be comfortable and relaxing for the mother and child. It is adduced that the infrequent use of side-lying position by mothers in this study may be associated with certain believes that the position is problematic to latch the baby on to the breast $[61,63]$, erroneous fears of infection from breast milk dripping to the baby's ears and possible risk of smothering and suffocation of baby when sleeping especially by obese mothers or those with large breasts.

Cross-cradle hold was the most reported baby hold techniques practiced by the mothers in this study. This finding is consistent with several non-refereed expert opinions. This breastfeeding hold-position is believed to allow for more control of the infant's head with just one arm while the mother put the breast in the mouth of the infant $[64,65]$. Football hold was also reported in this study as the second most practice hold technique among the mothers. This position is similar to tucking the baby under the arm like a football with the baby's feet extending across the body. The baby's head and shoulders are supported with the hand on the same side of the feeding breast [65]. It is important to note that breastfeeding hold is a dynamic practice, as mothers would constantly experiment with various positions and holds for their comfort and that of the child. However, this study sought mothers' assessment of their most usual breastfeeding hold practices. Although, mixed and variable breastfeeding position practices are common among mothers.

Baby-to-breast latch-on or attachment was the most common practice among the mothers. The latch-on position of baby on the breast has been reported to be a very important process in breastfeeding and in prevention of nipple soreness [66]. Teicher [67] submitted that the ability of the baby to actually obtain milk at breast is linked to baby-led latching; maternal positioning of herself and her baby for comfort. Baby-led latching which involves bringing the baby's body to the breast, adjusting mother or baby's position, and other techniques are important in resolving latch problems [67]. Therefore, mothers understanding of how to facilitate adequate contact between the baby's mouth and the mother's breast and how to recognize poor positioning are important areas of research [68]. Furthermore, the result of this study showed that majority of the mothers demonstrated a level of knowledge of breastfeeding ergonomics which include the use of arm support and foot rest and the posturing of the neck and back. Fitting the act of breastfeeding to the body through the use of supports and good postural alignment of the spine is ergonomic. These can help prevent breastfeeding related musculoskeletal disorders resulting from the effect of poor postures and positioning on joints, ligaments, and muscles. However, the framing of questions on ergonomics in this study did not allow the opportunity to choose more than one option. Future studies could explore a multiple choice or open ended assessment of ergonomic practices of breastfeeding mothers. Many mothers may have thought that footstools and pillows are advisable, but the busy and mobile lives of many mothers may have limited the practice.

\section{Conclusion}

Nigerian mothers demonstrated good knowledge and positive attitude towards breastfeeding. Breastfeeding was mostly believed to promote mother-baby bonding. Increasing length of time for maternity leave and providing designated areas at work places is believed to facilitate breastfeeding. Most of the mothers practiced advisable 
breastfeeding postures, preferred sitting on a chair to breastfeed and utilized cross-cradle hold and baby-tobreast latch-on.

\section{Competing interests}

The authors declare that they have no competing interests.

\section{Authors' contributions}

CEM conceived the idea for this study, participated in the design of methodology, data collection and analysis, interpretation of data and prepared the final manuscript for publication. AEO, JOF, FAF, AOO, TOA, AAO and OAA participated in the design of the study's methodology, interpretation of data and drafted the manuscript. FCO-A participated in the design of the study's methodology and data acquisition and drafted the manuscript. All authors read and approved the final manuscript.

\section{Acknowledgement}

The authors would like to acknowledge the administrative heads and the nursing staff of the Ife Hospital Unit of the Obafemi Awolowo University Teaching Hospital Complex (OAUTHC), Urban Comprehensive Health Centre (UCHC) of the OAUTHC, Eleyele, Enuwa Primary Health Center, Comprehensive Health Center Aderemi and Okeitubu Comprehensive Health Center Modakeke in Ile-lfe, for their support. Also, we would like to thank Mrs. Tolulope Olatunbosun for assisting in the pilot study.

\section{Author details}

${ }^{1}$ Department of Medical Rehabilitation, College of Health Sciences, Obafemi Awolowo University, Ile - Ife, Nigeria. ${ }^{2}$ Department of Nursing Sciences, Obafemi Awolowo University, Ile - Ife, Nigeria.

Received: 2 October 2013 Accepted: 18 December 2013 Published: 21 December 2013

\section{References}

1. Academy of Breastfeeding Medicine: Position on breastfeeding. 2008 http://www.bfmed.org. [Assessed 12/07/2011]

2. United Nations Children's Fund (UNICEF): Tracking progress on child and maternal nutrition: a survival and development priority. 2009. http:// www.unicef.org. Assessed 11/06/2012

3. Heckman JJ: Factors influencing milk production in nursing mothers. 2011. http://child-encyclopedia.com. [Assessed 12/04/12].

4. Singh K, Srivastava P: The effect of colostrums on infant mortality: urban rural differentials. Health and population. Perspect Issues 1992, 15(3\&4):94-100.

5. Okolo SN, Ogbonna C: Knowledge, attitude and practice of health workers in Keffi local government hospitals regarding baby-friendly hospital initiative (BFHI) practices. Eur J Clin Nutr 2002, 56(5):438-441.

6. Fergusson DM, Beautrais AL, Silva PA: Breast-feeding and cognitive development in the first seven years of life. Soc Sci Med 1982, 16:1705-1708.

7. United Nations Children's Fund (UNICEF): Breastfeeding: Foundation for a healthy future. 1999. http://www.unicef.org/publications/files/ pub_brochure_en.pdf. [Assessed 07/06/2012].

8. World Health Organization (WHO): The global strategy for infant and young child feeding. Geneva: WHO; 2003. http://whqlibdoc.who.int/publications/ 2003/9241562218.pdf.

9. Furman L, Minch NM, Hack M: Breastfeeding of very low birth weight. J-Hum-Lact 1998, 14(1):29-34

10. López-Alarcón M, Villalpando S, Fajardo A: Breast-feeding lowers the frequency and duration of acute respiratory infection and diarrhea in infants under six months of age. J Nutr 1997, 127(3):436-443.

11. Cushing AH, Samet JM, Lambert WE, Skipper BJ, Hunt WC, Young SA, McLaren LC: Breastfeeding reduces risk of respiratory illness in infants. Am J Epidemio/ 1998, 147(9):863-870.

12. Akobeng AK, Ramanan AV, Buchan I, Heller RF: Effect of breast feeding on risk of coeliac disease: a systematic review and meta-analysis of observational studies. Arch Dis Child 2006, 91:39-43.

13. Chantry CJ, Howard CR, Auinger P: Full breastfeeding duration and associated decrease in respiratory tract infection in US children. Pediatrics 2006, 117(2):425-432.

14. WHO/UNICEF: Innocenti declaration on the protection, promotion and support of breastfeeding. 1990. http://www.unicef.org/programme/ breastfeeding/innocenti.htm. [Accessed 12/08/2012].
15. Bonuck KA, Freeman K, Trombley M: Country of origin and race/ethnicity: impact on breastfeeding intentions. J-Hum-Lact 2005, 21(3):320-326.

16. Christopher K: Breastfeeding perceptions and attitudes: the effect of race/ethnicity and cultural background. Soc Today 2012, 10:2.

17. Narayan S, Natarajan N, Bawa KS: Maternal and neonatal factors adversely affecting breastfeeding in the perinatal period. MJAFI 2005, 61:216-219.

18. Bertino E, Varalda A, Magnetti F, Di Nicola P, Cester E, Occhi L, Perathoner C, Soldi A, Prandi G: Is breastfeeding duration influenced by maternal attitude and knowledge? A longitudinal study during the first year of life. J Matern Fetal Neonatal Med 2012, 25(3):32-36.

19. Heck KE, Braveman P, Cubbin C, Chávez GF, Kiely JL: Socioeconomic status and breastfeeding initiation among California mothers. Public Health Rep 2006, 121(1):51-59.

20. Flacking $\mathrm{R}$, Nyqvist $\mathrm{KH}$, Ewald U: Effects of socioeconomic status on breastfeeding duration in mothers of preterm and term infants. Eur J Public Health 2007, 17(6):579-584

21. Scott JA, Binns CW: Factors associated with the initiation and duration of breastfeeding: a review of the literature. Breastfeed Rev 1999, 7(1):5-16

22. Kronborg $\mathrm{H}$, Vaeth $\mathrm{M}$ : The influence of psychosocial factors on the duration of breastfeeding. Scand J Public Health 2004, 32(3):210-216.

23. Ogbonna C, Daboer JC: Current knowledge and practice of exclusive breastfeeding among mothers in Jos, Nigeria. Niger J Med 2007, 16(3):256-260

24. Agu U, Agu MC: Knowledge and practice of exclusive breastfeeding among mothers in a rural population in south eastern Nigeria. Trop $\mathrm{J}$ Med Res 2011, 15(2):39-44

25. Oche MO, Umar AS, Ahmed $\mathrm{H}$ : Knowledge and practice of exclusive breastfeeding in Kware, Nigeria. Afr Health Sci 2011, 11(3):518-523.

26. Ekanem IA, Ekanem AP, Asuquo A, Eyo VO: Attitude of working mothers to exclusive breastfeeding in Calabar municipality, cross river State, Nigeria. J Food Res 2012, 1(2):71-75.

27. Khassawneh M, Khader $Y$, Amarin Z, Alkafajei A: Knowledge, attitude and practice of breastfeeding in the north of Jordan: a cross-sectional study. Int Breastfeed J 2006, 23(1):17.

28. Ingram J: Multiprofessional training for breastfeeding management in primary care in the UK. Int Breastfeed J 2006, 1:9.

29. Singh B: Knowledge, attitude and practice of breast feeding - a case study. Euro J Sci Res 2010, 40(3):404-422.

30. Davies-Adetugbo AA: Sociocultural factors and the promotion of exclusive breastfeeding in rural Yoruba communities of Osun State, Nigeria. Soc Sci Med 1997, 45(1):113-125.

31. Agunbiade OM, Ogunleye OV: Constraints to exclusive breastfeeding practice among breastfeeding mothers in Southwest Nigeria: implications for scaling up. Int Breastfeed J 2012, 7:5

32. Abrahams SW, Labbok MH: Exploring the impact of the baby-friendly hospital initiative on trends in exclusive breastfeeding. Int Breastfeed J 2009, 4:11.

33. Barnes M, Cox J, Doyle B, Reed R: Evaluation of a practice-development initiative to improve breastfeeding rates. J Perinat Educ 2010, 19(4):17-23.

34. Bartington S, Griffiths LJ, Tate AR, Dezateux C, The Millennium Cohort Study Child Health Group: Are breastfeeding rates higher among mothers delivering in baby friendly accredited maternity units in the UK? Int $J$ Epidemio/ 2006, 35:1178-1186.

35. Ukegbu AU, Ukegbu PO, Onyeonoro UU, Ubajaka CF: Determinants of breastfeeding patterns among mothers in Anambra State, Nigeria. SAJCH 2011, 5(4):112-116.

36. Klaus MH, Kennell JH, Klaus PH: Bonding: building the foundations of secure attachment and independence. In Reading, Mass. Addison-Wesley Publishing; 1995.

37. Uvnäs-Moberg K, Eriksson M: Breastfeeding: physiological, endocrine and behavioural adaptations caused by oxytocin and local neurogenic activity in the nipple and mammary gland. Acta Paediatr 1996, 85(5):525-530.

38. Maisels MJ, Vain N, Acquavita AM, de Blanco NV, Cohen A, DiGregorio J: The effect of breast-feeding frequency on serum bilirubin levels. Am Obstet Gynecol 1994, 170:880-883.

39. Lin YY, Tsao P-N, Hsieh W-S, Chen C-Y, Chou H-C: The impact of breastfeeding on early neonatal jaundice. Clin Neonatol 2008, 15(1):31-35.

40. de Bruin NC, Degenhart HJ, Gàl S, Westerterp KR, Stijnen T, Visser HK: Energy utilization and growth in breast-fed and formula-fed infants measured prospectively during the first year of life. Am J Clin Nutr 1998, 67(5):885-896.

41. Dewey KG: Growth characteristics of breast-fed compared to formula-fed infants. Biol Neonate 1998, 74(2):94-105. 
42. Agostoni C, Grandi F, Giannì ML, Silano M, Torcoletti M, Giovannini M, Riva E: Growth patterns of breast fed and formula fed infants in the first 12 months of life: an Italian study. Arch Dis Child 1999, 81(5):395-399.

43. Ong G, Yap M, Foo LL, Tai BC: Impact of working status on breastfeeding in Singapore: evidence from the national breastfeeding survey 2001. Eur J Public Health 2005, 15(4):424-430.

44. Setegn T, Belachew T, Gerbaba M, Deribe K, Deribew A, Biadgilign S: Factors associated with exclusive breastfeeding practices among mothers in Goba district, south east Ethiopia: a cross-sectional study. Int Breastfeed J 2012, 7:17.

45. Sguassero Y: Optimal duration of exclusive breastfeeding: $\mathrm{RHL}$ commentary. In The WHO Reproductive Health Library. Geneva: World Health Organization; 2008

46. Kloeblen-Tarver AS, Thompson NJ, Miner KR: Intent to breast-feed: the impact of attitudes, norms, parity and experience. Am J Health Behav 2002, 26:182-187.

47. Hurley KM, Black MM, Papas MA, et al: Variation in breastfeeding behaviours, perceptions, and experiences by race/ethnicity among a low-income statewide sample of special supplemental nutrition program for women, infants and children (WIC) participants in the United States. Matern Child Nutr 2008, 4:95-105.

48. Persad MD, Mensinger JL: Maternal breastfeeding attitudes: association with breastfeeding intent and socio-demographics among urban primiparas. J Community Health 2008, 33:53-60.

49. Wojcicki JM, Gugig R, Tran C, Kathiravan S, Holbrook K, Heyman MB: Early exclusive breastfeeding and maternal attitudes towards infant feeding in a population of new mothers in San Francisco, California. Breastfeed Med 2010, 5(1):9-15.

50. Li L, Zhang M, Binns CW: Chinese mothers' knowledge and attitudes about breastfeeding in Perth, Western Australia. Breastfeed Rev 2003, 11(3):13-19.

51. Zhou Q, Younger KM, Kearney JM: An exploration of the knowledge and attitudes towards breastfeeding among a sample of Chinese mothers in Ireland. BMC Pub Health 2010, 10:722.

52. Scott JA, Landers MC, Hughes RM, Binns CW: Psychosocial factors associated with the abandonment of breastfeeding prior to hospital discharge. J-Hum Lact 2001, 17(1):24-30.

53. van den Berg M, Ball HL: Practices, advice and support regarding prolonged breastfeeding: a descriptive study from Sri Lanka. J Repro Infant Psychol 2008, 26(3):229-243.

54. Colson SD, Meek JH, Hawdon JM: Optimal positions for the release of primitive neonatal reflexes stimulating breastfeeding. Early Human Dev 2008, 84(7):441-449.

55. Ball HL: Reasons to bed-share: why parents sleep with their infants. J Repro Infant Psychol 2002, 20(4):207-221.

56. Milligan RA, Flenniken PM, Pugh LC: Positioning intervention to minimize fatigue in breastfeeding women. App Nurs Res 1996, 9(2):67-70.

57. Claus AP, Hides JA, Moseley GL, Hodges PW: Is 'ideal' sitting posture real? Measurement of spinal curves in four sitting postures. Man Ther 2009, 14:404-408.

58. Mbada CE, Oyinlola FC, Olatunbosun TO, Awotidebe TO, Arije OO, Johnson $\mathrm{OE}$, Fashote EO: Is baby-friendly breastfeeding mother-friendly? J Women's Health Phys Ther 2013, 37(1):19-28.

59. Colson S: Maternal breastfeeding positions, have we got it right? (1). Pract Midwife 2005, 8(10):24-27.

60. UNICEF UK Baby Friendly Initiative \& the Health Promotion Agency for Northern Ireland: Teaching breastfeeding skills. 2008. http://www. healthpromotionagency.org.uk/Resources/breastfeeding/pdfs/Breastfeeding. [Accessed 07/06/13].

61. Royal College of Midwives: Home birth. In Position paper 25. London; 2002. 5(1):26-29.

62. Kapandji IA: The physiology of the joints. Vol.3. In The trunk and the vertebral column. 2nd edition. Edinburgh: Churchill Livingstone; 1974

63. Renfrew M, Fisher C, Arms S: Breastfeeding: Getting breastfeeding right for you. Berkeley: Celestial Arts; 1990:35-71.

64. Ayushveda US: Different postures for breastfeeding. 2009. http://www.us. ayushveda.com. [Assessed 12/04/2012]

65. Weiss RE: Positions for breastfeeding your baby - cradle hold, football hold, cross cradle. http://pregnancy.about.com. [Assessed 12/04/2012]
66. Vireday P: Breastfeeding after a cesarean. 2002. http://www.plus-sizepregnancy.org. [Assessed 14/04/2012]

67. Teicher $\mathrm{MH}$ : Restoration and recovery. Chapter 10. In Impact of birthing practices on breastfeeding. 2nd edition. Edited by Smith LJ. USA: Jones and Bartlett Publishers; 2004:108-220.

68. Minchin MK: Positioning for breastfeeding. Birth 1989, 16(2):67-80.

doi:10.1186/1756-0500-6-552

Cite this article as: Mbada et al:: Knowledge, attitude and techniques of breastfeeding among Nigerian mothers from a semi-urban community. BMC Research Notes 2013 6:552.

\section{Submit your next manuscript to BioMed Central and take full advantage of:}

- Convenient online submission

- Thorough peer review

- No space constraints or color figure charges

- Immediate publication on acceptance

- Inclusion in PubMed, CAS, Scopus and Google Scholar

- Research which is freely available for redistribution

Submit your manuscript at www.biomedcentral.com/submit
C) BioMed Central 